\title{
Poly(ester amide)s based on (L)-lactic acid oligomers and $\alpha$-amino acids: influence of the $\alpha$ - amino acid side chain in the poly(ester amide)s properties
}

Ana C. Fonseca, Jorge F.J. Coelho, Joana F.A. Valente, Tiago R. Correia , Ilídio J. Correia, Maria H. Gil \& Pedro N. Simões

To cite this article: Ana C. Fonseca, Jorge F.J. Coelho, Joana F.A. Valente, Tiago R. Correia, llídio J. Correia , Maria H. Gil \& Pedro N. Simões (2013) Poly(ester amide)s based on (L)-lactic acid oligomers and $\alpha$-amino acids: influence of the $\alpha$-amino acid side chain in the poly(ester amide)s properties, Journal of Biomaterials Science, Polymer Edition, 24:12, 1391-1409, DOI: 10.1080/09205063.2012.762293

To link to this article: https://doi.org/10.1080/09205063.2012.762293

View supplementary material $₫$

曲 Published online: 25 Jan 2013.

Submit your article to this journal ๘

Џll Article views: 128

Citing articles: 5 View citing articles $\longleftarrow$ 


\title{
Poly(ester amide)s based on (L)-lactic acid oligomers and $\alpha$-amino acids: influence of the $\alpha$-amino acid side chain in the poly(ester amide)s properties
}

\author{
Ana C. Fonseca ${ }^{\mathrm{a} *}$, Jorge F.J. Coelho ${ }^{\mathrm{a}}$, Joana F.A. Valente ${ }^{\mathrm{b}}$, Tiago R. Correia ${ }^{\mathrm{b}}$, Ilídio J. \\ Correia $^{\mathrm{b}}$, Maria H. Gil ${ }^{\mathrm{a}}$ and Pedro N. Simões ${ }^{\mathrm{a}}$ \\ ${ }^{a}$ Department of Chemical Engineering, University of Coimbra, Polo II, Rua Silvio Lima, Coimbra \\ 3030-790, Portugal; ${ }^{b}$ CICS-Health Sciences Research Center, University of Beira Interior, Av. Infante D. \\ Henrique, Covilhã 6201-506, Portugal
}

(Received 22 October 2012; accepted 21 December 2012)

\begin{abstract}
Novel biodegradable and low cytotoxic poly(ester amide)s (PEAs) based on $\alpha$-amino acids and (L)-lactic acid (L-LA) oligomers were successfully synthesized by interfacial polymerization. The chemical structure of the new polymers was confirmed by spectroscopic analyses. Further characterization suggests that the $\alpha$-amino acid plays a critical role on the final properties of the PEA. L-phenylalanine provides PEAs with higher glass transition temperature, whereas glycine enhances the crystallinity. The hydrolytic degradation in PBS $(\mathrm{pH}=7.4)$ at $37^{\circ} \mathrm{C}$ also depends on the $\alpha$-amino acid, being faster for glycine-based PEAs. The cytotoxic profiles using fibroblast human cells indicate that the PEAs did not elicit an acute cytotoxic effect. The strategy presented in this work opens the possibility of synthesizing biodegradable PEAs with low citotoxicity by an easy and fast method. It is worth to mention also that the properties of these materials can be fine-tuned only by changing the $\alpha$-amino acid.
\end{abstract}

Keywords: $\alpha$-amino acids; (L)-lactic acid oligomers; interfacial polycondensation; degradation; biocompatibility

\section{Introduction}

The interest in synthetic biodegradable polymers for biomedical applications has increased significantly along the recent years. Until now, most of the studies have focused on the development and application of aliphatic polyesters, such as poly(lactic acid), poly(lacticco-glycolic acid) and poly(e-caprolactone). However, their application is sometimes limited by their low thermal and mechanical properties and poor interaction with cells. In order to overcome such limitations, an increasing interest has been paid to PEAs.[1] PEAs are a family of synthetic polymers whose structure includes both ester and amide linkages, and whose properties lie between those of polyesters and polyamides. The presence of the amide linkages promotes intra- and intermolecular hydrogen bonding, hence contributing to the thermal and mechanical properties of the PEAs. In turn, the biodegradability of the PEAs is ensured by the presence of the ester linkage.[2] PEAs containing $\alpha$-amino acids and $\alpha$-hydroxy acids (e.g. L-LA or glycolic acid) in their structure, commonly known as

\footnotetext{
*Corresponding author. Email: anafs@eq.uc.pt
} 
polydepsipeptides, are a particular family of PEAs whose importance in biomedical field is well recognized.[1,3,4] Upon degradation, such PEAs release common metabolites in the human body ( $\alpha$-amino acids and $\alpha$-hydroxy acids), and for that reason, the toxicity induced by these materials is very low. Furthermore, given that the degradation products have both acid and basic natures, a neutralization effect occurs, thus preventing the accentuated $\mathrm{pH}$ decrease, commonly observed in polyesters degradation. Additionally, the presence of the $\alpha$-amino acid gives to the material the capacity of being degraded by enzymatic pathways.[5,6]

PEAs with different properties can be obtained by simply changing the $\alpha$-amino acid pendant group. Different side chain groups influence important properties such as crystallinity degree, chain flexibility, and hydrophilic/hydrophobic balance. Such properties have an important role in the biodegradation behaviour of PEAs as well as in their interaction with cells.[7]

In this work, PEAs based on glycine, L-phenylalanine and L-LA were prepared by interfacial polymerization, using a diamine derived from the above-mentioned $\alpha$-amino acids and a diacyl chloride derived from L-LA oligomers. Interfacial polymerization was the selected approach since it is a fast and simple polycondensation method, in which the polymer is obtained within few hours of reaction (viz. $3 \mathrm{~h}$ ). [8] The preparation of PEAs by interfacial polymerization using conventional diamines $[9,10]$ and diamines based on $\alpha$-amino acids [11] has been reported in literature. However, the proposed synthesis of the diamines based on $\alpha$-amino acids is quite complicated, involving troublesome protection/deprotection steps of the $\alpha$-amino acids functional groups, even for the simplest $\alpha$-amino acid.[11] In our strategy, the $\alpha$-amino acid based diamines were obtained by a Fischer esterification between the $\alpha$-amino acid and the chosen diol, in the presence of $p$-toluene sulfonic acid monohydrate. It is a simple method that has been successfully used for the synthesis of this type of monomers.[7,12,13] The L-LA oligomers were prepared by the melt polycondensation of L-lactic acid, which is a less expensive synthesis route when compared to the conventional ring opening polymerization of L-lactide.

\section{Experimental}

\subsection{Materials}

L-LA (80\%), ethylene glycol (EG) (99\%), di-ethylene glycol (DEG) (99\%), poly(ethylene glycol) (PEG, $\left.M_{\mathrm{n}}=300 \mathrm{~g} \mathrm{~mol}^{-1}\right), \quad p$-toluenesulfonic acid monohydrate ( $p$-TSA), glycine (>99\%), L-phenylalanine (>98\%), sebacoyl chloride $(92 \%)$, anhydrous sodium carbonate $\left(\mathrm{Na}_{2} \mathrm{CO}_{3}\right), N, N^{\prime}$-dimethylformamide (HPLC grade) and chloroform (HPLC grade) were purchased from Sigma-Aldrich (St Louis, USA), and used as received. Dichloromethane, toluene and acetone were supplied by José Manuel Gomes dos Santos Lda (Odivelas, Portugal) and were purified by standard methods before use.[14] Deuterated dimethylsulfoxide (DMSO- $d_{6}$ ) was purchased from Eurisotop (France).

Dulbecco's modified Eagle's medium (DMEM-F12), ethylenediaminetetraacetic acid (EDTA), lactate dehydrogenase (LDH) assay, L-glutamine, 3-(4,5-dimethylthiazol-2-yl)5-(3-carboxymethoxyphenyl)-2-(4-sulphofenyl)-2H-tetrazolium inner salt (MTS), penicillin G, phosphate-buffered saline solution (PBS), streptomycin, amphotericin B and trypsin were purchased from Sigma-Aldrich (Sintra, Portugal). Human fibroblast cells (Normal Human Dermal Fibroblasts adult, criopreserved cells) were purchased from PromoCell (Labclinics, S.A.; Barcelona, Spain). Fetal bovine serum (FBS) was purchased from Biochrom AG (Berlin, Germany). 


\subsection{Synthesis procedures}

\subsubsection{Synthesis of bis( $\alpha$-amino acid) esters}

A suspension of the $\alpha$-amino acid (glycine or L-phenylalanine) (27.5 mmol), DEG (12.5 mmol) and $p$-TSA $(30 \mathrm{mmol})$ in toluene (Scheme 1) was heated up to $130{ }^{\circ} \mathrm{C}$ under stirring, in a round-bottom flask equipped with a Dean-Stark apparatus and a condenser with a drying tube. The suspension was kept under reflux until no more water was distilled. The excess of toluene was removed using reduced pressure and the products were recovered by recrystallization. The bis( $\alpha$-amino acid) ester derived from glycine and DEG (1) was recrystallized from an isopropanol/ethyl acetate mixture, whereas the bis $(\alpha$-amino acid) ester derived from L-phenylalanine and DEG (2) was recrystallized from water.[5,15,16]

Elemental analysis for $\mathrm{C}_{22} \mathrm{H}_{32} \mathrm{~N}_{2} \mathrm{O}_{11} \mathrm{~S}_{2}$ (1): Calculated - C 46.80\%; H 5.67\%; N 4.96\%; Found - C 46.92\%; H 5.86\%; N 5.52\%. Yield: $48 \%$.

${ }^{1} \mathrm{H}$ NMR (DMSO- $\left.d_{6}, \delta, \mathrm{ppm}\right): 7.49-7.13(8 \mathrm{H}, \mathrm{Ar}-\mathrm{H}), 4.28\left(4 \mathrm{H}, \mathrm{COOCH}_{2} \mathrm{CH}_{2}\right), 3.85$ $\left(4 \mathrm{H}, \mathrm{NH}_{3}{ }^{+} \mathrm{CH}_{2}\right), 3.68\left(4 \mathrm{H}, \mathrm{COOCH}_{2} \mathrm{CH}_{2}\right), 2.29\left(6 \mathrm{H}, \mathrm{Ar}-\mathrm{CH}_{3}\right)$.

IR spectra $\left(\mathrm{cm}^{-1}\right): 1755\left(v \mathrm{C}=\mathrm{O}_{\text {ester }}\right), 1212$ and $1177\left(v \mathrm{C}-\mathrm{O}-\mathrm{C}_{\text {ester }}\right), 1129\left(v \mathrm{C}-\mathrm{O}-\mathrm{C}_{\text {ether }}\right)$, 1030 and $1010\left(v_{\text {as }} \mathrm{SO}_{3}^{-}, v_{\mathrm{s}} \mathrm{SO}_{3}^{-}\right.$, respectively).

Elemental analysis for $\mathrm{C}_{36} \mathrm{H}_{44} \mathrm{~N}_{2} \mathrm{O}_{11} \mathrm{~S}_{2}$ (2): Calculated - C 58.05\%; H 5.91\%; N 3.76\%; Found - C 58.55\%; H 5.80\%; N 3.8\%. Yield: $52 \%$.

${ }^{1} \mathrm{H}$ NMR (DMSO-d $\left.d_{6}, \delta, \mathrm{ppm}\right): 7.49-7.11(18 \mathrm{H}, \mathrm{Ar}-\mathrm{H}), 4.29\left(2 \mathrm{H}, \mathrm{NH}_{3}{ }^{+} \mathrm{CHCH}_{2} \mathrm{Ph}\right), 4.22$, $4.17\left(4 \mathrm{H}, \mathrm{COOCH}_{2} \mathrm{CH}_{2}\right), 3.54,3.48\left(4 \mathrm{H}, \mathrm{COOCH}_{2} \mathrm{CH}_{2}\right), 3.12,3.04\left(4 \mathrm{H}, \mathrm{CH}_{2} \mathrm{Ph}\right), 2.29(6 \mathrm{H}$, $\left.\mathrm{Ar}-\mathrm{CH}_{3}\right)$.

IR spectra $\left(\mathrm{cm}^{-1}\right)$ : $1736\left(v \mathrm{C}=\mathrm{O}_{\text {ester }}\right), 1229$ and $1177\left(v \mathrm{C}-\mathrm{O}-\mathrm{C}_{\text {ester }}\right), 1129\left(v \mathrm{C}-\mathrm{O}-\mathrm{C}_{\text {ether }}\right)$, 1039 and $1014\left(v_{\mathrm{as}} \mathrm{SO}_{3}^{-}, v_{\mathrm{s}} \mathrm{SO}_{3}^{-}\right.$, respectively).

\subsubsection{Synthesis of L-LA telechelic oligomers}

For the preparation of L-LA oligomers with -OH terminal groups (PLA-OH) and different central units, L-LA was copolymerized with EG or PEG $(10 \mathrm{~mol} \%$ relative to the amount of L-LA). The polymerization was carried out in the melt for $13 \mathrm{~h}$, at atmospheric pressure and $170^{\circ} \mathrm{C}$ (Scheme 2). During the reaction, a continuous stream of nitrogen was maintained under the surface of the melt. The oligomers were purified by a dissolution (acetone)/precipitation (water) method. The excess of solvent was evaporated under vacuum, and the viscous liquid oligomer was placed in a vacuum oven, at $40^{\circ} \mathrm{C}$, for four days.[17,18] PLA-OH 1:

$\bar{M}_{\mathrm{n}}=598 \mathrm{~g} \mathrm{~mol}^{-1}, \bar{M}_{\mathrm{w}} / \bar{M}_{\mathrm{n}}=1.32 ;$ PLA-OH $2: \bar{M}_{\mathrm{n}}=600 \mathrm{~g} \mathrm{~mol}^{-1}, \bar{M}_{\mathrm{w}} / \bar{M}_{\mathrm{n}}=1.18$

\subsubsection{Synthesis of PEAs}

The PEAs were synthesized by interfacial polymerization between diacyl chlorides derived from the L-LA oligomers and the bis( $\alpha$-amino acid) esters derived from glycine and L-phenylalanine.

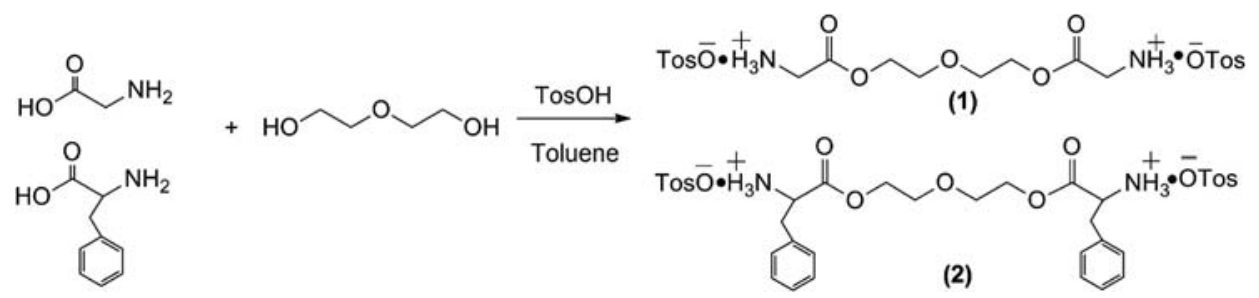

Scheme 1. Reaction between the $\alpha$-amino acids and DEG, to yield bis( $\alpha$-amino acid esters). 
<smiles>CC(O)C(=O)O</smiles>

$$
\mid \begin{aligned}
& \mathrm{T}=170^{\circ} \mathrm{C} \\
& \mathrm{P}_{\mathrm{atm}} \\
& 13 \mathrm{~h}
\end{aligned}
$$<smiles>[Y]C(OCCOC(=O)C(C)OC(=O)C(C)O)C(=O)OCCOC(=O)C(C)OC(C)C(=O)C(C)O</smiles>

PLA-OH1

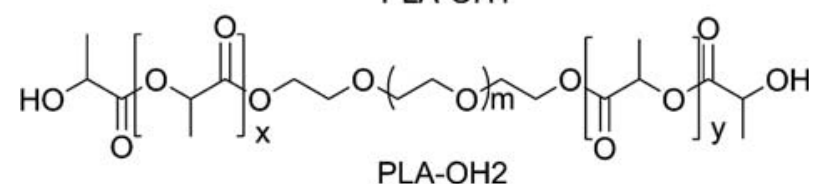

Scheme 2. Reaction between L-LA and EG and L-LA and PEG.

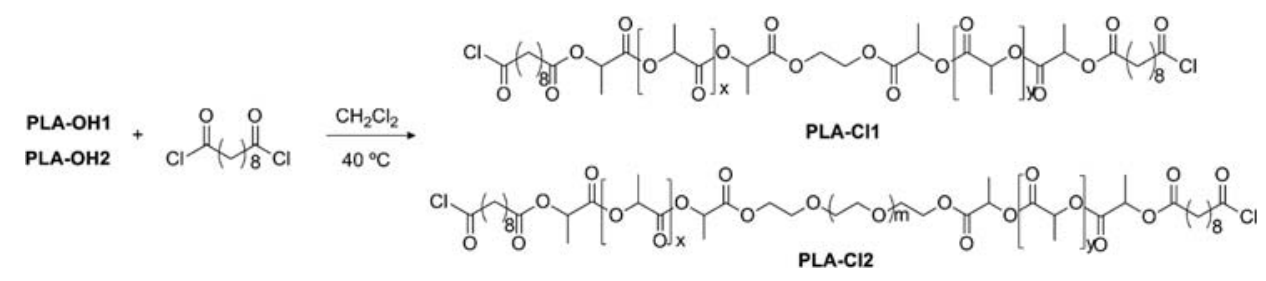

Scheme 3. Reaction between L-LA telechelic oligomers and sebacoyl chloride.

2.2.3.1. Synthesis of diacyl chloride derived from L-LA oligomers. The L-LA telechelic oligomers $(3 \mathrm{mmol})$ were dissolved in dichloromethane $(4.5 \mathrm{~mL})$ and added dropwise to a stirred solution of sebacoyl chloride $(6 \mathrm{mmol})$ in dichloromethane $(4.5 \mathrm{~mL})$, at $40^{\circ} \mathrm{C}$. The reaction was allowed to proceed for $2 \mathrm{~h}$ (Scheme 3). [10,11]

2.2.3.2. Interfacial polymerization of (1) and (2) with PLA-Cl 1 and PLA-Cl 2. (1) or (2) $(6 \mathrm{mmol})$ was dissolved in distilled water $(18 \mathrm{~mL}) \cdot \mathrm{Na}_{2} \mathrm{CO}_{3}(12 \mathrm{mmol})$ was added and the resulting solution was placed in an ice bath. Next, the organic solution prepared in the previous step was added dropwise to the aqueous solution under stirring. The reaction was allowed to proceed for $2 \mathrm{~h}$ (Scheme 4). The precipitated polymer was recovered by filtration, washed thoroughly with acetone, distilled water and dried under vacuum.[10,11]

\subsection{Characterization techniques}

\subsubsection{Chemical structure identification}

Elemental composition of the bis( $\alpha$-amino acid) esters was determined using an elemental analyzer EA1108 CHNS-O from Fisons Instruments.

Fourier transform infrared (FT/IR) spectra were obtained in the range $4000-500 \mathrm{~cm}^{-1}$ at room temperature using a Jasco FT/IR-4200 spectrometer, equipped with a Golden Gate 


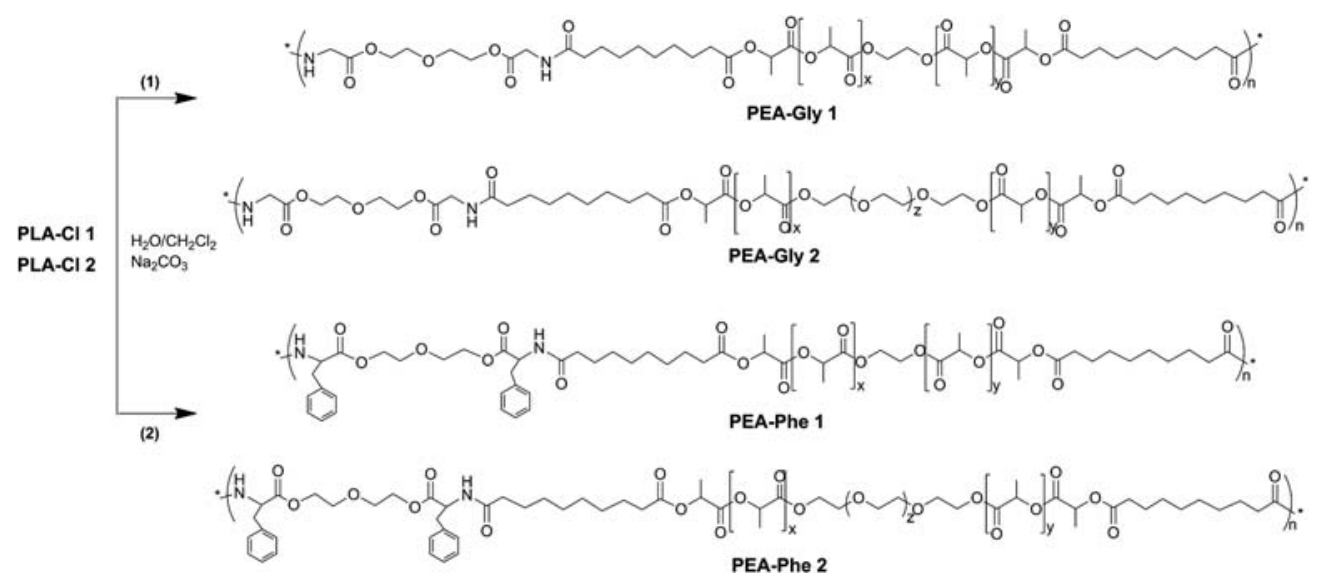

Scheme 4. Reaction between the bis( $\alpha$-amino acid) esters and L-LA-derived diacyl chlorides.

Single Reflection Diamond ATR. Data collection was performed with $4 \mathrm{~cm}^{-1}$ spectral resolution and 128 accumulations.

${ }^{1} \mathrm{H}$ NMR spectra were obtained in deuterated dimethylsulfoxide (DMSO- $d_{6}$ ), at $25^{\circ} \mathrm{C}$, on a Varian Unity $600 \mathrm{MHz}$ Spectrometer using a $3 \mathrm{~mm}$ broadband NMR probe. Tetramethylsilane (TMS) was used as internal standard.

\subsubsection{Molecular weight distribution}

The number-average $\left(\bar{M}_{\mathrm{n}}\right)$ and weight-average $\left(\bar{M}_{\mathrm{w}}\right)$ molecular weight of the L-LA oligomers were determined by size-exclusion chromatography (SEC) using two PLgel MIXED-D columns (Polymer Laboratories) coupled to an evaporative light scattering detector, PL-EMD 960. Chloroform was used as eluent and the system was calibrated with narrow polystyrene standards.

The molecular weight distribution of the PEAs was determined using a HPSEC, Viscotek (Dual detector 270, Viscotek, Houston, USA) with a differential viscosimetry (DV) detector, and refractive index (RI) detector (Knauer K-2301). The column set consisted of a PL $10 \mu \mathrm{m}$ guard column $(50 \mathrm{~mm} \times 7.5 \mathrm{~mm})$ followed by two MIXED-B PL columns $(300 \mathrm{~mm} \times 7.5 \mathrm{~mm}$, $10 \mu \mathrm{m}$ ). HPLC pump (Knauer K-1001) was set with a flow rate of $1 \mathrm{~mL} \mathrm{~min}^{-1}$. The system was also equipped with a Knauer on-line degasser. The tests were done at $60^{\circ} \mathrm{C}$ using an Elder CH-150 heater. The samples were filtered through a PTFE membrane with $0.2 \mathrm{~mm}$ pore, before the injection $(100 \mu \mathrm{L})$. DMF with $\mathrm{LiBr}(0.03 \% \mathrm{w} / \mathrm{w})$ was used as the eluent. Universal calibration was done with four narrow polystyrene standards $\left(\bar{M}_{\mathrm{p}}\left(\mathrm{g} \mathrm{mol}^{-1}\right)\right)=1820$; $4290 ; 10,050 ; 30,300)$.

\subsubsection{Thermal properties}

The thermal stability of PEAs was firstly evaluated by simultaneous thermal analysis (STA: heat-flux DSC and TGA), using a TA Instruments SDT Q600 equipment (thermobalance sensitivity: $0.1 \mu \mathrm{g}$ ), which was previously calibrated in the range $25-1000^{\circ} \mathrm{C}$ by running tin and lead as melting standards, at a heating rate $(\phi)$ of $10^{\circ} \mathrm{C} \mathrm{min}^{-1}$, using open alumina crucibles and a dry nitrogen purge flow of $100 \mathrm{~mL} \mathrm{~min}^{-1}$. Sample weights ranging from 8 to $10 \mathrm{mg}$ were used. At least two runs were performed for each sample. 
The thermal behaviour of PEAs was further studied by modulated differential scanning calorimetry (MDSC) in a TA Instruments Q100 model equipped with a RCS90 cooling unit. The heat flow and the heat capacity were calibrated at $2{ }^{\circ} \mathrm{C} \mathrm{min}^{-1} \mathrm{using}$, respectively, indium and sapphire standards. The samples were analysed in aluminum pans with an ordinary aluminium lid loosely placed. Sample weights ranging from 5 to $10 \mathrm{mg}$ were used. A heating rate of $2{ }^{\circ} \mathrm{C} \mathrm{min}^{-1}$, a modulation period of $60 \mathrm{~s}$, and a temperature modulation of $\pm 0.40^{\circ} \mathrm{C}$ were applied. A dry nitrogen purge flow of $50 \mathrm{~mL} \mathrm{~min}^{-1}$ was used in all measurements. For glass transition temperature measurements, a heating/cooling cycle from 25 to $190{ }^{\circ} \mathrm{C}$ and from this temperature to $-85^{\circ} \mathrm{C}$ was performed to eliminate the thermal history, after which the samples were heated at $2{ }^{\circ} \mathrm{C} \mathrm{min}^{-1}$ from -85 to $190^{\circ} \mathrm{C}$. The values of glass transition temperature were obtained from the corresponding heat capacity step (half-height), obtained from the reversing signal. At least two runs were performed for each sample.

Dynamic mechanical thermal analysis (DMTA) was carried out in a Tritec 2000 DMA. The runs were performed using PEAs in powder form, placed in stainless steel material pockets, in a single cantilever bending geometry. The tests were carried out from -150 to $190^{\circ} \mathrm{C}$, in multifrequency mode, with a standard heating rate of $2^{\circ} \mathrm{C} \mathrm{min}^{-1}$.

\subsubsection{In vitro degradation}

In vitro hydrolytic degradation tests were done in $\mathrm{PBS}(\mathrm{pH}=7.4)$, at $37^{\circ} \mathrm{C}$, for 40 days. Then, $20 \mathrm{mg}$ of PEA samples were immersed in $5 \mathrm{~mL}$ of PBS and incubated at $37^{\circ} \mathrm{C}$. At predetermined times, PBS was removed and the sample washed with distilled water and centrifuged. This procedure was repeated for three times. Then, the PEA was dried under vacuum until no weight change was observed. The degree of degradation was estimated from the weight loss of the PEA according to the Equation (1):

$$
\text { Weight loss }(\%)=\frac{W_{0}-W_{t}}{W_{0}} \times 100
$$

where $W_{0}$ is the initial weight of the dry samples before immersion, and $W_{t}$ is the dry PEA sample weight after incubation for $t$ days.

\subsubsection{In vitro biocompatibility studies}

2.3.5.1. Proliferation of human fibroblasts cells in the presence of the PEAs. Human Fibroblasts cells were seeded in T-flasks of $25 \mathrm{~cm}^{2}$ with $6 \mathrm{~mL}$ of DMEM-F12 supplemented with heat-inactivated FBS (10\% v/v) and 1\% antibiotic/antimycotic solution. After the cells become confluent, they were subcultivated by a $3-5$ min incubation in $0.18 \%$ trypsin $(1: 250)$ and $5 \mathrm{mM}$ EDTA. Subsequently, cells were centrifuged, resuspended in culture medium and then seeded in T-flasks of $75 \mathrm{~cm}^{2}$. Hereafter, cells were kept in culture at $37^{\circ} \mathrm{C}$ in a $5 \% \mathrm{CO}_{2}$ humidified atmosphere, inside an incubator. To evaluate cell behaviour in the presence of the materials, fibroblasts cells were seeded with materials in 96-well plates at a density of $15 \times 103$ cells per well, for $72 \mathrm{~h}$. The materials were sterilized by UV irradiation for $30 \mathrm{~min}$, before being placed in contact with cells. Cell growth was monitored using an Olympus CX41 inverted light microscope (Tokyo, Japan) equipped with an Olympus SP-500 UZ digital camera.[19,20] The materials' morphology with/without cells was analysed by SEM. To evaluate cell adhesion and proliferation, human fibroblast cells were seeded with materials. After two days of culture, the samples were fixed overnight with $2.5 \%$ glutaraldehyde in PBS at $4{ }^{\circ} \mathrm{C}$. Hereafter, samples were rinsed three times with distilled water for 2 min and dehydrated in graded ethanol of 70, 80, 90, and $100 \%$, for $5 \mathrm{~min}$ each.[21] Subsequently, the materials were mounted on stubs using a 
double-side adhesive tape and sputter coated with gold using an Emitech K550 sputter coater (London, UK). The SEM images were acquired with a SEM Hitachi S-2700 (Tokyo, Japan) with an acceleration voltage of $20 \mathrm{kV}$ at different magnifications.[22]

2.3.5.2. Characterization of the cytotoxic profile of PEAs. Human fibroblasts cells were seeded in the presence of the different PEAs, in 96-well plate, with $100 \mu 1$ of DMEM-F12 and following incubated at $37^{\circ} \mathrm{C}$, in a $5 \% \mathrm{CO}_{2}$ humidified atmosphere. After predetermined incubation periods $(24,48$ and $72 \mathrm{~h}$ ), cell viability was assessed through the reduction of the MTS into a water-soluble formazan product. Briefly, the medium of each well was removed and replaced with a mixture of $100 \mu \mathrm{L}$ of fresh culture medium and $20 \mu \mathrm{L}$ of MTS/PMS reagent solution. Then, cells were incubated for $4 \mathrm{~h}$ at $37^{\circ} \mathrm{C}$, under a $5 \% \mathrm{CO}_{2}$ humidified atmosphere. The absorbance was measured at $492 \mathrm{~nm}$ using a microplate reader (Sanofi, Diagnostics Pauster). Wells containing cells in the culture medium without materials were used as negative controls $(\mathrm{K}-)$. Ethanol $(96 \%)$ was added to wells that contained cells, as a positive control $(\mathrm{K}+) \cdot[21,23,24]$ Moreover, a LDH assay was also performed. In this assay, the amount of extracellular LDH released from damage cells was measured as an indicator of cytotoxicity. After 24, 48 and $72 \mathrm{~h}$ in the presence of materials, the well plates were shaken briefly to homogenize the release $\mathrm{LDH}$ into the culture medium and then $50 \mu \mathrm{L}$ of this medium was transferred into a fresh 96-well plate. Then, the LDH assay mixture $(100 \mu \mathrm{L})$ was added to each well. After 20-30 min, the enzymatic activity was stopped by the addition of hydrochloric acid. Then, the absorbance of the samples was measured at $492 \mathrm{~nm}$. Wells containing cells in the culture medium without materials were used as negative control. Lysis solution was added to wells containing cells to be used as positive control.

\section{Results and discussion}

\subsection{Synthesis of L-LA telechelic oligomers and their chemical structure identification}

The synthesis of L-LA oligomers with hydroxyl terminal groups was carried out in the melt, without catalysts, using L-LA, in the presence of EG or PEG as co-monomers. It is expected that the diols react with a molecule of L-LA or a small L-LA oligomeric chain, yielding oligomeric chains with hydroxyl terminal groups.[17,18] As the polymerization proceeds, the carboxylic groups of L-LA monomer or L-LA oligomeric chain react with the hydroxyl groups of the telechelic chain. As a result, at the end of the polymerization, the final product should have only one type of terminal group.[17]

The structural features of the L-LA oligomers were investigated by FTIR and ${ }^{1} \mathrm{H}$ NMR spectroscopies. Figure 1 presents the FTIR spectra of the L-LA oligomers with hydroxyl terminal groups. The wavenumbers corresponding to the characteristic bands and respective assignments are presented in supporting information (Table S1).

Further information about the structural features of L-LA oligomers was provided by ${ }^{1} \mathrm{H}$ NMR analysis shown in Figure 2.

Here, it is possible to observe the resonances corresponding to the central units of L-LA oligomers, as well as those corresponding to the terminal hydroxyl groups. The resonances in the 5.2-4.96 ppm range are attributed to the $-\mathrm{CH}$ (e) groups of L-LA central units. The signals in the $1.5-1.35 \mathrm{ppm}$ range correspond to the $-\mathrm{CH}_{3}$ (d) groups of the L-LA oligomeric chain, including those linked to the EG or PEG central unit. In the $4.3-4.1 \mathrm{ppm}$ range it is possible to observe the resonances of the $-\mathrm{CH}$ (b) protons from the hydroxylated end units, together with the $-\mathrm{CH}_{2}$ protons of the EG or PEG linked to the L-LA oligomeric chain. The well-separated resonances in the 1.3-1.2 ppm range correspond to the $-\mathrm{CH}_{3}$ (c) protons of the hydroxyl end units.[25] These resonances are common to both L-LA oligomers, as expected. 

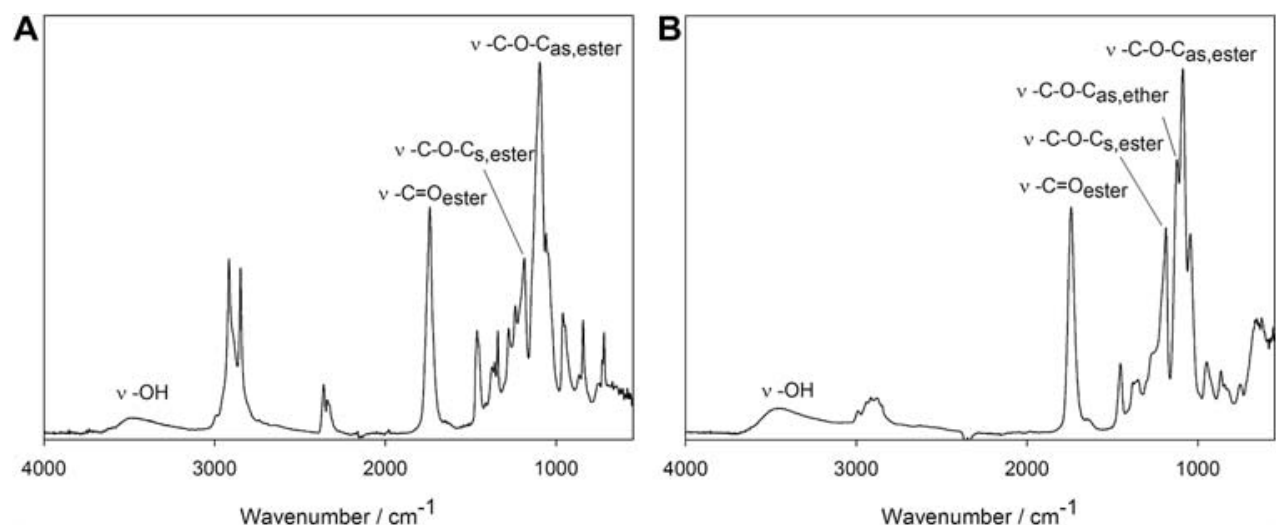

Figure 1. FTIR spectra of the L-LA oligomers with hydroxyl terminal groups and an ethylene glycol central unit (A); and a poly(ethylene glycol) central unit (B).

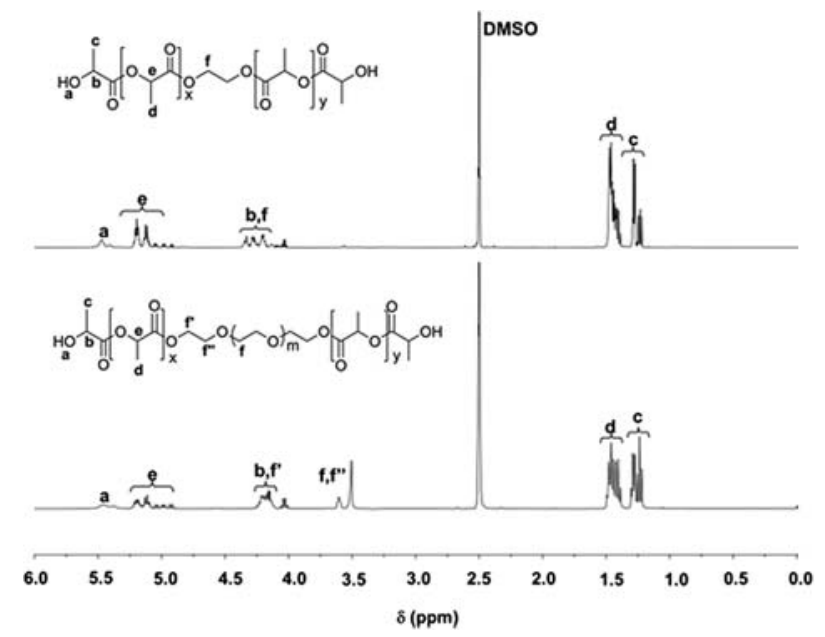

Figure 2. ${ }^{1} \mathrm{H}$ NMR spectra of the L-LA hydroxyl-terminated oligomers.

The only difference lies in the resonances of the L-LA oligomers central unit. For PLA-OH 1 , the resonance corresponding to the $-\mathrm{CH}_{2}$ (f) protons of EG should appear near $4.36 \mathrm{ppm}$. However, this peak is overlapped by the resonance of the $-\mathrm{CH}$ protons from the hydroxylated end units of the L-LA oligomeric chain units. In PLA-OH 2, the resonance corresponding to central $-\mathrm{CH}_{2}$ ( $\mathrm{f}, \mathrm{f}$ ') protons of PEG chain is well resolved, appearing at 3.5 and $3.6 \mathrm{ppm}$. The resonance at about $5.47 \mathrm{ppm}$ (a) observed in both spectra can be attributed to the protons of the hydroxyl terminal groups.

Taking into account the obtained results, it is possible to conclude that the L-LA oligomers with $-\mathrm{OH}$ terminal groups were successfully obtained and can be used as precursors for the synthesis of PEAs.

\subsection{Synthesis of PEAs and their chemical structure identification}

The PEAs were synthesized by interfacial polymerization between glycine- and L-phenylalanine-based bis( $\alpha$-amino acid) esters and L-LA oligomers-based diacyl chlorides. $\mathrm{Na}_{2} \mathrm{CO}_{3}$ was 
used as acid acceptor for $p$-TSA in order to regenerate free amino groups in the bis $(\alpha$-amino acid) ester.

The molecular weight distribution (MWD) of the PEAs was measured by SEC (universal calibration) using the viscosity measured by the on-line viscosimeter. Figure 3(A) shows the SEC traces (RI and DV) obtained for the PEA-Gly1. It is possible to observe a linear dependence of $\log \mathrm{Mw} v s$ retention time, which indicates a proper separation of the samples in the set of columns used. The use of an on-line viscosimeter allowed the measurement of the viscosity directly from the detector and the determination of the Mark-Houwink-Sakurada constants (Figure 3(B)) for this polymer, in the experimental conditions used. These parameters are particularly important since it is known the difficulty to determine accurately the PEAs MWD.[1]

Table 1 presents the molecular weights of the four synthesized PEAS.

The PEAs MW is rather low, predictably due to a low availability of acyl chloride functionalities necessary to react with the $\alpha$-amino acid based diamines. In principle, this fact can be ascribed to: the low functionality of the L-LA oligomers necessary to form the macrodiacyl chloride (see Scheme 3); and/or the hydrolysis of the macrodiacyl chloride during the interfacial polymerization that decreases the availability of acyl chloride functionalities to react with the $\alpha$-amino acid-based diamine. Nevertheless, it is interesting to note that the MW and PDI obtained for the different PEAs are similar regardless the starting monomers used. It is worth to mention that the same procedure was used to synthesize the PEAs. Therefore, it can be stated that both $\alpha$-amino acids-based diamines and L-LA-based diacyl chlorides should have similar reactivities. Regarding $\mathrm{d} n / \mathrm{d} c$, the obtained values demonstrate that this property depends on the $\alpha$-amino acid used, but is not dependent on the central unit of the L-LA oligomeric segment. Taking into account that these values are relatively low, the analysis of the PEAs using the light-scattering detector is very difficult.

The chemical structure of the PEAs was investigated by FTIR and ${ }^{1} \mathrm{H}$ NMR spectroscopies. Figure 4 presents the FTIR spectra of the synthesized PEAs.
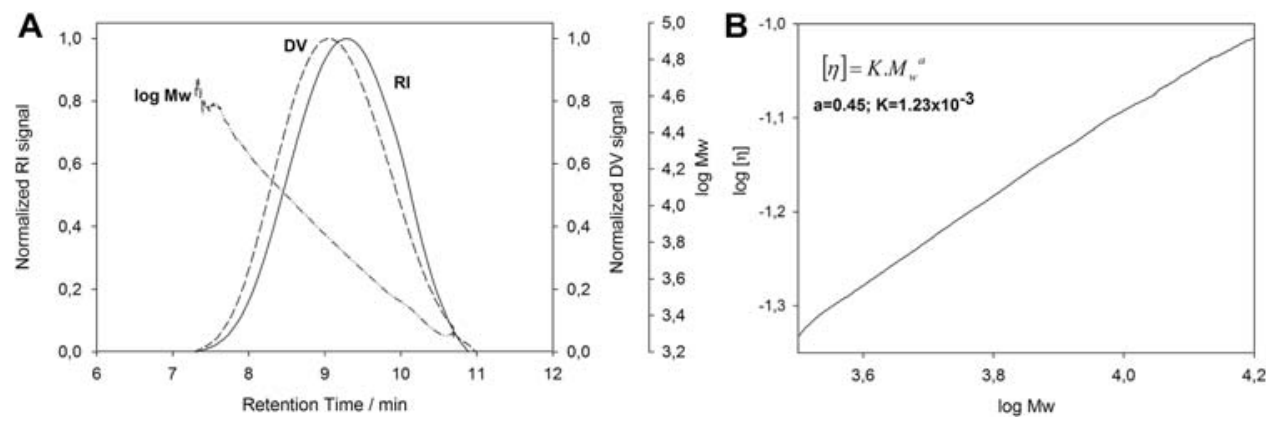

Figure 3. Normalized RI and DV signals $v s$ retention time (A) and $\log [\eta] v s \log \mathrm{Mw}(\mathrm{B})$ for PEA-Gly1.

Table 1. Molecular weight, PDI and $\mathrm{d} n / \mathrm{d} c$ values for the PEAs.

\begin{tabular}{lccc}
\hline Poly(ester amide) & $\overline{M_{\mathrm{n}}}(\mathrm{Da})$ & PDI & $\mathrm{d} n / \mathrm{d} c\left(\mathrm{ml} \mathrm{g}^{-1}\right)$ \\
\hline PEA-Gly 1 & 4.200 & 1.62 & 0.049 \\
PEA-Gly 2 & 4.900 & 1.37 & 0.043 \\
PEA-Phe 1 & 4.700 & 1.51 & 0.064 \\
PEA-Phe 2 & 4.800 & 1.67 & 0.067 \\
\hline
\end{tabular}



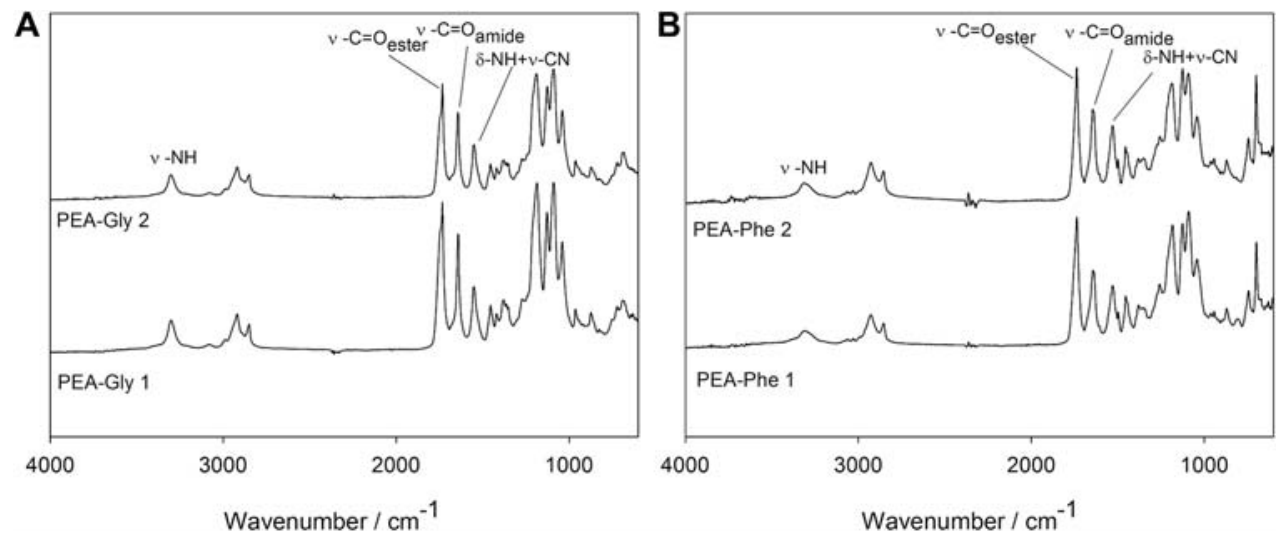

Figure 4. FTIR spectra of the PEAs: (A) containing glycine; and (B) containing L-phenylalanine.

Here, it is possible to observe the bands corresponding to the ester and amide linkages. The Amide A $(v-\mathrm{NH})$ band is relatively broad and appears in a wavenumber zone that indicates that the $-\mathrm{NH}$ group is involved in a H-bond. The absence of shoulders above $3380 \mathrm{~cm}^{-1}$ indicates the absence of free $\mathrm{N}-\mathrm{H}$ groups.[26,27] The bands corresponding to the $v \mathrm{C}=\mathrm{O}_{\text {ester }}$ appear in a wavenumber range that is characteristic of non H-bonded ester groups. Additionally, the wavenumber corresponding to the Amide I band is characteristic of $\mathrm{C}=\mathrm{O}_{\text {amide }} \mathrm{H}$-bonded groups.[28] Thus, one can conclude that, in the synthesized PEAs, the prevailing interaction established at ambient temperature is a $\mathrm{H}$-bond of the type $N_{\text {amide }}-\mathrm{H} \ldots$ $\mathrm{O}_{\text {amide }}=$. The wavenumbers corresponding to the characteristic bands, with the respective assignments are presented in supporting information (Table S2).

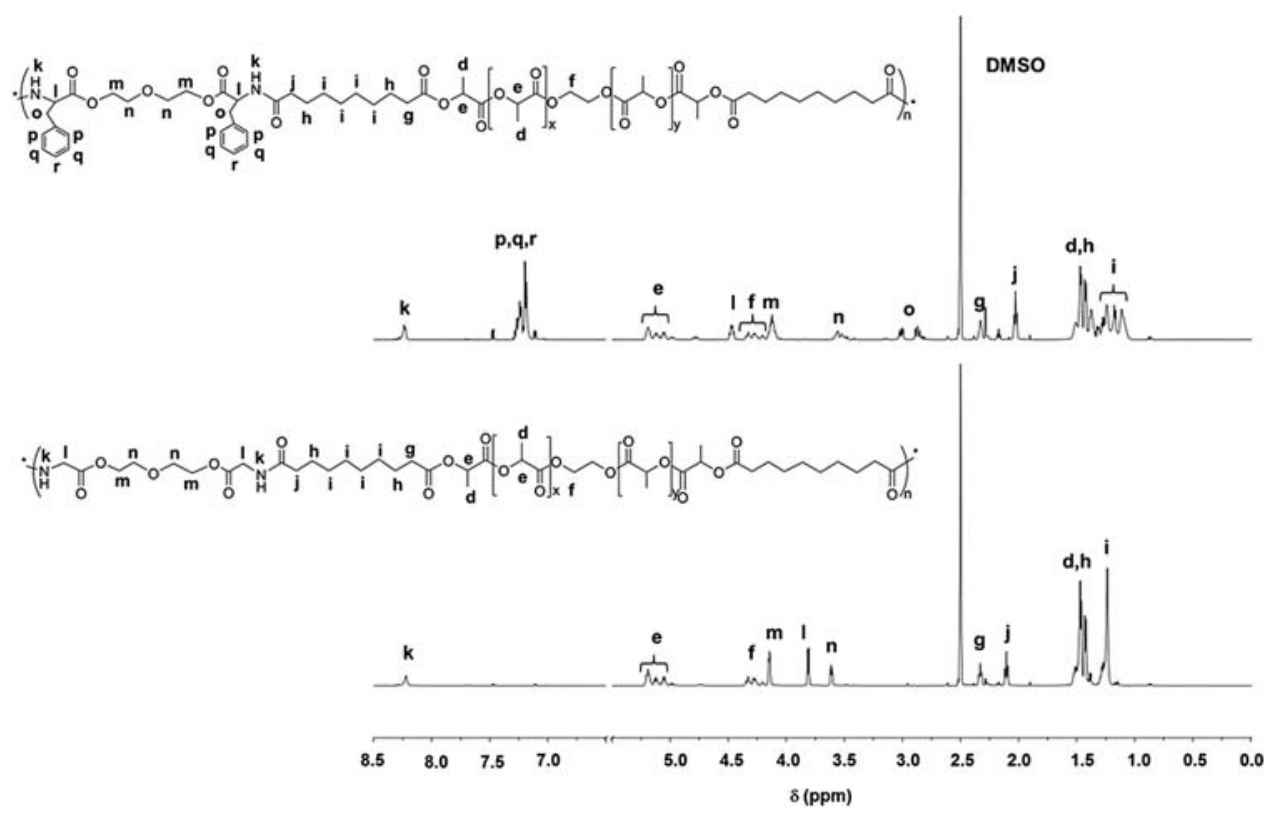

Figure 5. ${ }^{1} \mathrm{H}$ NMR spectra of the PEAs synthesized from the L-LA diacyl chlorides containing an ethylene glycol central unit. 
Further insights on the PEAs structure were provided by ${ }^{1} \mathrm{H}$ NMR spectroscopy.

The ${ }^{1} \mathrm{H}$ NMR spectra (Figure 5) presents the resonances of the protons of the PEAs synthesized from the L-LA diacyl chlorides containing an EG central unit and respective assignments. The ${ }^{1} \mathrm{H}$ NMR spectra of the remaining PEAs are shown in supporting information (Figure $\mathrm{S} 1$ ). The resonance of the amide protons $(\mathrm{k})$ is clearly visible at $\delta \sim 8.23 \mathrm{ppm}$ for all PEAs. It is interesting to note that the resonance of the $-\mathrm{CH}_{3}$ protons (c) belonging to the hydroxyl end units of the L-LA oligomeric chain (Figure 2) does not appear in the ${ }^{1} \mathrm{H}$ NMR spectra of the PEAs. This is indicative that the L-LA oligomeric chain was incorporated in the PEAs through an ester linkage. Besides, due to the incorporation of the L-LA chain, the terminal $-\mathrm{CH}_{2}$ protons of sebacoyl chloride are linked to an ester linkage in one side, and to an amide linkage in the other side. Thus, it is expected that such $-\mathrm{CH}_{2}$ groups present different chemical shifts. This is corroborated by the presence of two distinct resonances ( $g$ and $j$ ) in the ${ }^{1} \mathrm{H}$ NMR spectra of the prepared PEAs. In the PEAs based on L-phenylalanine, the resonances corresponding to the aromatic ring protons are clearly visible $(p, q, r)$.

The data provided by FTIR and ${ }^{1} \mathrm{H}$ NMR spectroscopies are in full agreement with the proposed chemical structure of the PEAs (Scheme 4), and thus one can conclude that the polymers were successfully synthesized.

\subsection{Thermal properties of the PEAs}

The thermal events and the thermal stability of the synthesized PEAs were evaluated by simultaneous thermal analysis (STA, TGA/DSC), in a $25-600{ }^{\circ} \mathrm{C}$ temperature range. Additionally, the thermal transitions of the synthesized PEAs, below degradation temperature, were studied in detail by MDSC and dynamic mechanical thermal analysis (DMTA). Table 2 presents the relevant temperatures taken from the thermal analysis.

It is possible to see that the thermal stability of the PEAs is not highly dependent on the lateral group of the $\alpha$-amino acid, since only slight variations are observed in the $T_{\text {on }}$ and $T_{10 \%}$ values of the PEAs. Regarding the weight loss pattern (see supporting information, Figure S2), the TGA analysis revealed that the PEAs under study present two degradation stages. Analogous behaviour has been found for different types of PEAs.[5,9,29] No weight loss is observed at temperatures below the main mass loss stages, indicating the absence of sub-products or oligomers with low thermal stability. In the light of the available information in literature, the first stage of weight loss can be ascribed to the cleavage of ester linkages along with ether linkages, whereas the second stage can be ascribed to the cleavage of amide linkages, which are known to be thermally more stable.[30]

Regarding the thermal events of the PEAs below degradation temperature, the MDSC analysis revealed that glycine-based PEAs have a well-defined melting endotherm (Table 2

Table 2. Characteristic quantities obtained from STA (TG/DSC), MDSC and DMTA analysis. $T_{\text {on }}$ : extrapolated onset temperatures (STA-TG); $T_{10 \%}$ : temperature corresponding to $10 \%$ of mass loss (STA-TG); $T_{\mathrm{d}}$ : degradation temperature of the PEAs (STA-DSC); $T_{\mathrm{m}}$ : melting temperature (MDSC); $T_{\mathrm{g}}$ (MDSC and DMTA). The uncertainties correspond to the standard deviation.

\begin{tabular}{lcccccc}
\hline PEA & $T_{\mathrm{on}}\left({ }^{\circ} \mathrm{C}\right)$ & $T_{10 \%}\left({ }^{\circ} \mathrm{C}\right)$ & $T_{\mathrm{d}}\left({ }^{\circ} \mathrm{C}\right)^{\mathrm{a}}$ & $T_{\mathrm{m}}\left({ }^{\circ} \mathrm{C}\right)^{\mathrm{a}}$ & $T_{\mathrm{g} \text { DSC }} /{ }^{\circ} \mathrm{C}$ & $T_{\mathrm{g} \text { DMTA }} /{ }^{\circ} \mathrm{C}$ \\
\hline PEA-Gly 1 & $300.0 \pm 0.2$ & $299.2 \pm 0.8$ & $335.3 \pm 0.1$ & $126.6 \pm 0.2$ & $0.15 \pm 0.1$ & -2 \\
PEA-Gly 2 & $296.7 \pm 1.1$ & $301.1 \pm 1.9$ & $354.3 \pm 0.0$ & $120.6 \pm 0.2(53 \pm 0.0)$ & $-8.94 \pm 0.1$ & -9.1 \\
PEA-Phe 1 & $308.2 \pm 0.4$ & $296.7 \pm 1.9$ & $351.4 \pm 1.3$ & $\times$ & $13.67 \pm 0.3$ & 9.9 \\
PEA-Phe 2 & $313.9 \pm 0.9$ & $301.3 \pm 1.5$ & $359.3 \pm 2.1$ & $\times$ & $2.84 \pm 0.1$ & -1.1 \\
\hline
\end{tabular}

${ }^{\mathrm{a}}$ The temperatures presented correspond to peak temperatures. 
and Figure S3(A) from supporting information), demonstrating their semi-crystalline character. PEA-Gly 1 presents a melting endotherm at $c a .127^{\circ} \mathrm{C}$ and no additional peaks are detected. PEA-Gly 2, in turn, has an endotherm at $c a .120^{\circ} \mathrm{C}$ and presents an additional peak at $c a$. $53{ }^{\circ} \mathrm{C}$ (Table 2). Thus, in PEA-Gly 2 two crystalline phases should exist: one attributed to the segments containing the amide linkage and the other to the L-LA segments.[9,11] Regarding the PEAs containing L-phenylalanine in their structure, none of them showed melting peak, revealing their amorphous character (Figure S3(B) from supporting information). The bulky side groups of L-phenylalanine prevent a close chain packing, and hence the crystallization. [7] In fact, research works dealing with the preparation of $\alpha$-amino acid-based PEAs have reported a significant decrease in the crystallinity as the $\alpha$-amino side group becomes more voluminous.[5,31-33]

The glass transition temperatures $\left(T_{\mathrm{g}}\right)$ of the synthesized PEAs were determined by MDSC and DMTA (Table 2). The different values of $T_{\mathrm{g}}$ are explained by the differences in the definition of the glass transition among the two techniques.[34] Nevertheless, in both analyses the values of $T_{\mathrm{g}}$ follow the same tendency. PEA-Gly 2 and PEA-Phe 2 present a $T_{\mathrm{g}}$ value lower than PEA-Gly 1 and PEA-Phe 1, respectively. The former group of PEAs presents PEG in their structure and consequently a higher density of ether linkages, which are known to be quite flexible linkages for free rotation. Thus, the flexibility of the polymeric chain increases, promoting the chain segmental movement that leads to a decrease in the $T_{\mathrm{g}}$ value.[16] The higher values of $T_{\mathrm{g}}$ correspond to the PEAs containing L-phenylalanine in the structure (PEA-Phe 1 and PEA-Phe 2). This result was expected since the aromatic side group of L-phenylalanine provides stiffness, contributing to motion restrictions in the polymeric main chain, thus increasing the $T_{\mathrm{g}}$ value. All the PEAs present a single glass transition, which indicates the total miscibility between the L-LA oligomeric segments and the amide linkages containing segments.

\subsection{In vitro degradation of the PEAs}

The hydrolytic degradation under simulated physiological conditions $\left(\mathrm{pH}=7.4 \mathrm{PBS}, 37^{\circ} \mathrm{C}\right.$ ) was studied and the weight loss pattern of the synthesized PEAs is shown in Figure 6.

Here, it is possible to observe that the weight loss of the different samples increases continuously with time. The PEAs containing glycine have a faster weight loss than those containing L-phenylalanine. It is known that the degradation of polymeric materials depends mainly on their molecular weight and degree of crystallinity.[35,36] The results provided by SEC analysis revealed that the PEAs have a similar molecular weight. However, in what concerns the crystallinity, MDSC analysis showed that the glycine-based PEAs have a semi-crystalline nature, whereas the L-phenylalanine-based PEAs are amorphous. In semi-crystalline polymers (e.g. polyesters), the degradation starts in the amorphous region and only after in the crystalline region. Since in the amorphous regions the polymeric chains are loosely packed, it is easier for the degradation medium to penetrate in such regions. When most of the amorphous regions are degraded, the degradation proceeds to the crystalline domains.[35,36] Based on these observations, it was expected that the L-phenylalanine-based PEAs presented higher weight loss than their glycine counterparts, contrarily to what was observed. Therefore, it seems that the lateral group of the L-phenylalanine has a key role in PEA-Phe 1 and PEA-Phe 2 hydrolytic degradation behaviour. Since the lateral group of L-phenylalanine is highly hydrophobic, it makes the penetration of the aqueous degradation medium into the PEAs structure more difficult, thus diminishing the degradation rate.

Regarding the influence of the central unit of the L-LA diacyl chloride (see Scheme 4), it is possible to see that the PEAs containing the L-LA diacyl chloride with a PEG central block 


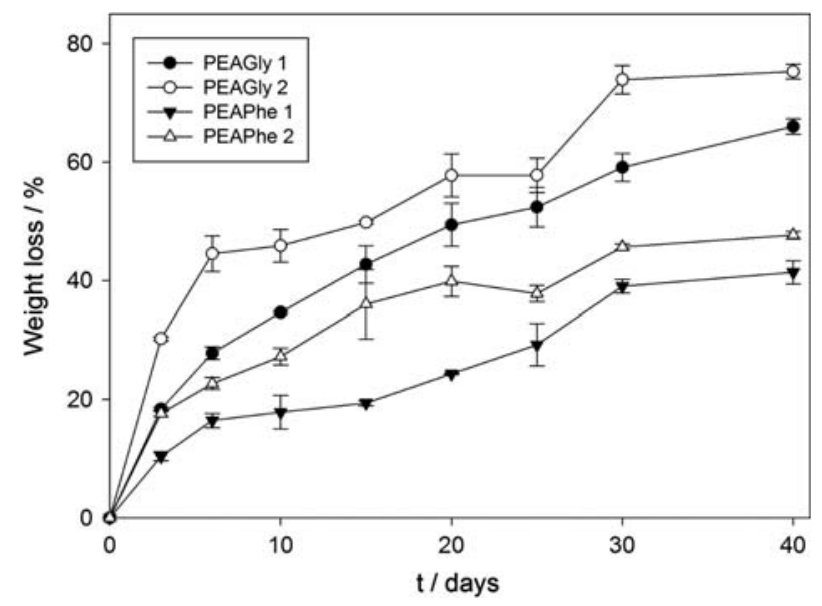

Figure 6. Weight loss of PEAs degraded in $\mathrm{pH}=7.4 \mathrm{PBS}$ at $37^{\circ} \mathrm{C}$.

(PEA-Gly 2 and PEA-Phe 2) degrade faster than those containing EG (PEA-Gly 1 and PEAPhe 1). The presence of PEG (highly hydrophilic molecule) in the polymer backbone should increase the affinity of the PEAs towards the aqueous degradation medium, accelerating the hydrolytic degradation. [37,38]

Studies conducted on the hydrolytic degradation of different PEAs showed that they degrade through the ester-bond cleavage,[36,39,40] whereas the amide linkage remains essentially intact. Compositional changes of PEAs during the hydrolytic degradation were evaluated by FTIR by comparing the band areas ratios of the $v \mathrm{C}=\mathrm{O}_{\text {ester }}$ and $v \mathrm{C}=\mathrm{O}_{\text {amide, }}$, in the region of $1600-1800 \mathrm{~cm}^{-1}$. The different samples present a decrease in the area ratio of $v \mathrm{C}=\mathrm{O}_{\text {ester }}$ to $v \mathrm{C}=\mathrm{O}_{\text {amide }}$ as the hydrolysis time increases, indicating that the ester linkages degrade faster than the amide linkages [41] (see Table S3 in supporting information).

\subsection{In vitro citotoxicity of the PEAs}

As previously mentioned, human fibroblasts cells were seeded at the same initial density in the 96-well plates, with or without the PEAs to assess their cytotoxicity. Cell adhesion and proliferation was characterized using an inverted light microscope (Figure 7).

Figure 7 shows that cells adhered and grew in the presence of the materials and in the negative control. A higher number of cells was observed in the presence of glycine-based PEAs, after $72 \mathrm{~h}$. For PEAs containing L-phenylalanine, a lower number of cells was observed, after the same period of time, which can be related with the hydrophobic nature of L-phenylalanine-based PEAs. Previous in vitro cytotoxicity studies conducted with fibroblasts showed that the cells proliferated better in more hydrophilic materials.[42,43] In the positive control, no cell adhesion or proliferation was observed. Dead cells with their typical spherical shape were visualized.

PEAs were also characterized by SEM in order to obtain high-resolution images of PEAs morphology with or without human fibroblasts cells seeded on their surface. SEM images showed that PEAs have a high level of microporosity and roughness (Figure 8 (A), (C), (E) and $(\mathrm{G})$, which is essential for both cell growth and nutrient transport.[44] Human fibroblasts cells formed focal adhesions and assembled stress fibres on polymers surface, which is fundamental for cell survival (see Figure 8(B), (D), (F) and (H)). 

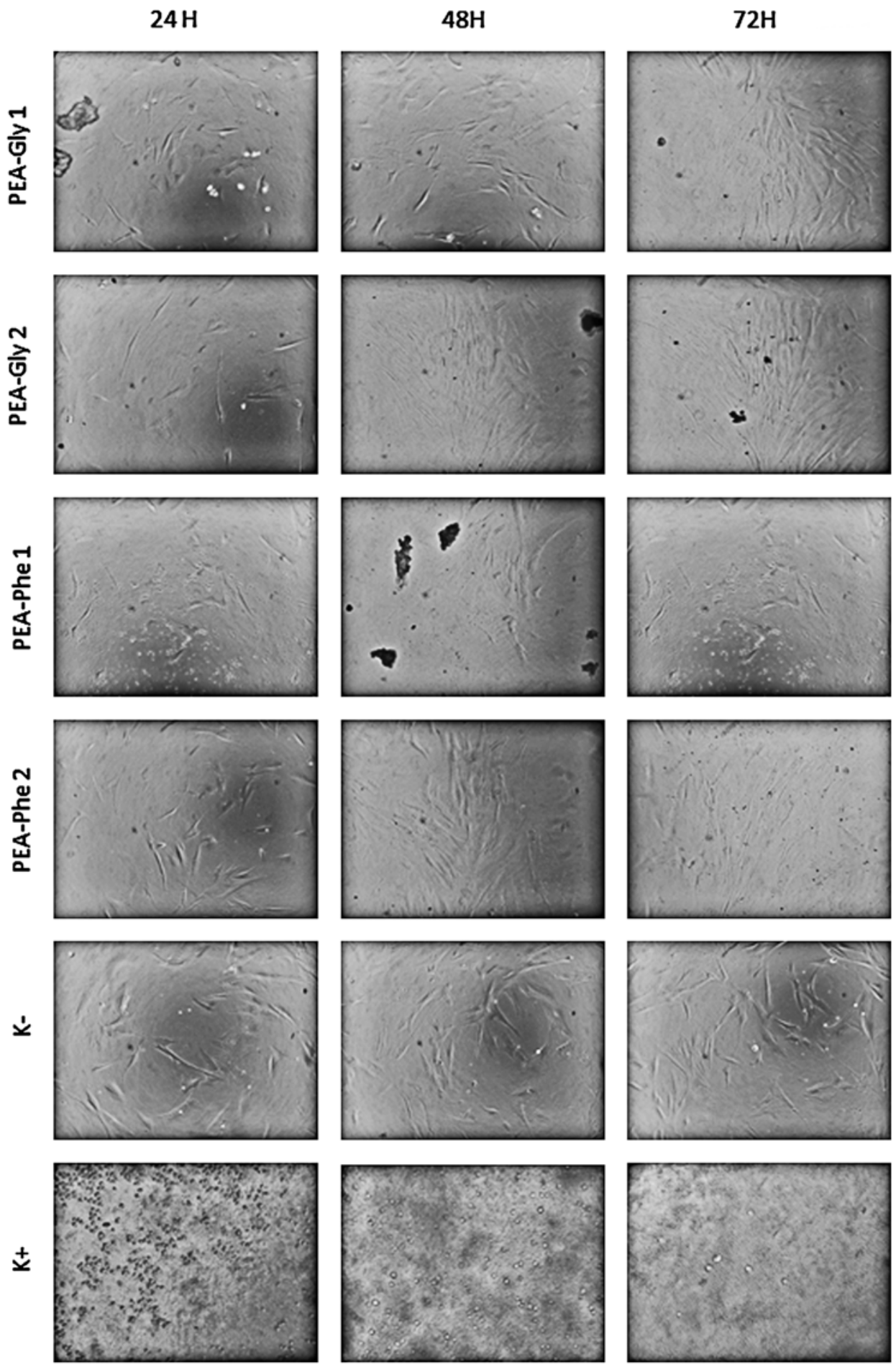

Figure 7. Microscopic photographs of human fibroblasts cells seeded in the presence of the different PEAs after 24, 48 and $72 \mathrm{~h}$.

$\mathrm{K}-$, negative control; $\mathrm{K}+$, positive control. Original magnification $\times 100$. 

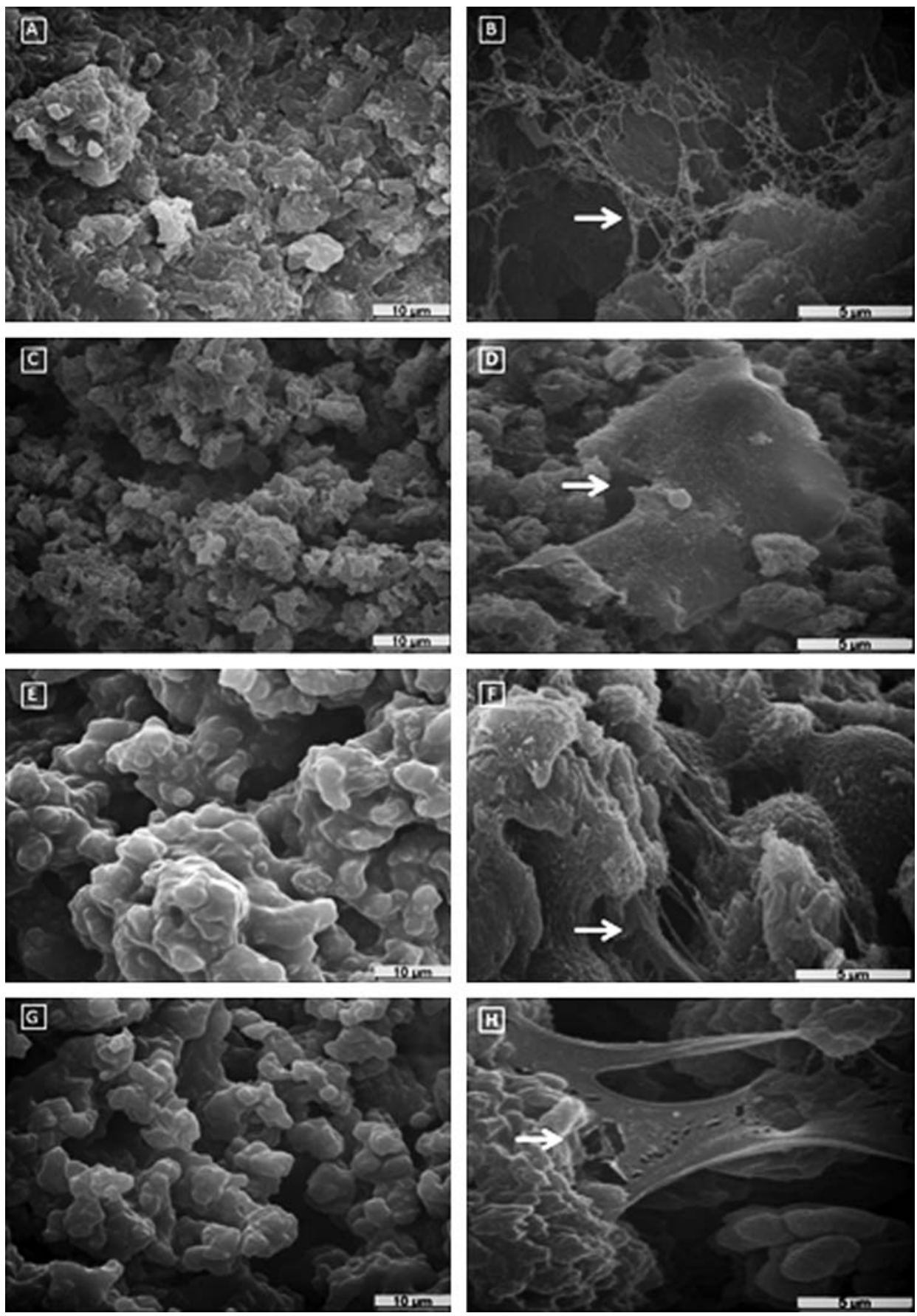

Figure 8. SEM images of PEAs at different magnifications: (A) PEA-Gly 1; (C) PEA-Gly 2; (E) PEAPhe 1; (G) PEA-Phe 2. (B), (D), (F) and (H) show human fibroblasts cells adhered to the surface of the different samples. White arrows illustrate human cells. 

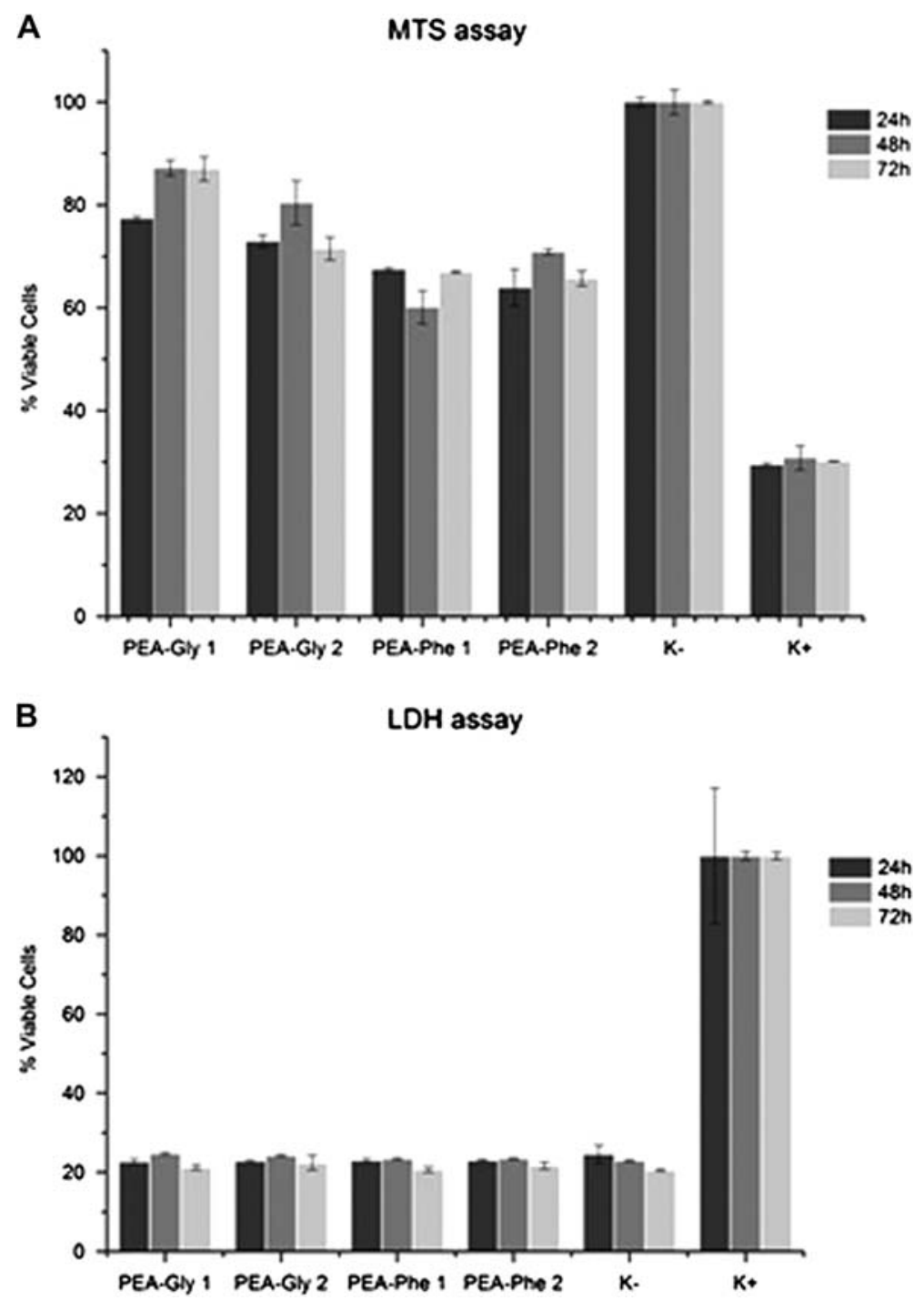

Figure 9. Cellular activities measured by the MTS assay (A) and LDH assay (B) after 24, 48 and $72 \mathrm{~h}$; Positive control $(\mathrm{K}+)$; negative control $(\mathrm{K}-)$.

Additionally, MTS and LDH assays were also performed in order to further characterize materials cytotoxic profile. The MTS assay results (Figure 9(A)) showed that cells in presence of tested samples had higher viability than the positive control, but slightly lower than the negative control. This indicates that the PEAs do not provoke an acute toxic effect in the cells. The LDH assay results (Figure 9(B)) are in agreement with those obtained for the MTS assay. Thus, it is possible to conclude that the human fibroblast cell membrane integrity was not significantly affected after 24,48 and $72 \mathrm{~h}$ of being seeded in the presence of the materials.

The results herein presented show that none of the samples affected significantly cell integrity or viability, which is very important for the biomedical applications proposed for these materials. 


\section{Conclusions}

Four different PEAs based on $\alpha$-amino acids and L-LA oligomers were successfully synthesized by interfacial polymerization. The chemical structures were confirmed by spectroscopic analysis. All the synthesized PEAs present a similar molecular weight and PDI. The lateral group of the $\alpha$-amino acid showed to have important influence in the thermal properties of the PEAs as well as in their hydrolytic degradation behaviour. The cytotoxic profile of the PEAs was evaluated using fibroblasts human cells and it was found that the materials did not elicit an acute toxic effect in the cells. The new polymers synthesized in this work can be used as building blocks in more complex structures to enhance both the degradability in physiological medium and biocompatibility of such structures.

The data presented in this manuscript provides the scientific community with a straightforward method for the preparation of PEAs based on $\alpha$-amino acids and $\alpha$-hydroxy acids. This fact is particularly relevant knowing the potential of these materials in biomedical applications.

\section{Supplementary material}

The supplementary material for this paper is available online at http://dx.doi.org/10.1080/ 09205063.2012.762293.

\section{Acknowledgement}

A.C. Fonseca acknowledges "Fundação para a Ciência e Tecnologia", Grant: SFRH/BD/41305/2007. The ${ }^{1} \mathrm{H}$ NMR data were obtained from Rede Nacional de RMN in the University of Coimbra, Portugal. The Varian VNMRS $600 \mathrm{MHz}$ spectrometer is part of the National NMR Network and was purchased in the framework of the National Program for Scientific Re-equipment (contract REDE/1517/RMN/2005, with funds from POCI 2010 (FEDER) and Fundação para a Ciência e Tecnologia (FCT)). I.J. Correia acknowledges the project PTDC/EME-TME/103375/2008 for financial support.

\section{References}

[1] Sun H, Meng F, Dias AA, Hendriks M, Feijen J, Zhong Z. Alpha-amino acid containing degradable polymers as functional biomaterials: Rational design, synthetic pathway, and biomedical applications. Biomacromolecules. 2011;12:1937-1955.

[2] Rodriguez-Galan A, Franco L, Puiggali J. Degradable poly(ester amide)s for biomedical applications. Polymers. 2011;3:65-99.

[3] Feng Y, Lu J, Behl M, Lendlein A. Progress in depsipeptide-based biomaterials. Macromol. Biosci. 2010;10:1008-1021.

[4] Feng YK, Guo JT. Biodegradable polydepsipeptides. Intern. J. Mol. Sci. 2009;10:589-615.

[5] Armelin E, Paracuellos N, Rodriguez-Galan A, Puiggali J. Study on the degradability of poly(ester amide)s derived from the alpha-amino acids glycine, and L-alanine containing a variable amide/ ester ratio. Polymer. 2001;42:7923-7932.

[6] Montane J, Armelin E, Asin L, Rodriguez-Galan A, Puiggali J. Comparative degradation data of polyesters and related poly(ester amide)s derived from 1.4-butanediol sebacic acid, and alphaamino acids. J. Appl. Polym. Sci. 2002;85:1815-1824.

[7] Karimi P, Rizkalla AS, Mequanint K. Versatile biodegradable poly(ester amide)s derived from amino acids for vascular tissue engineering. Materials. 2010;3:2346-2368.

[8] Odian G. Principles of polymerization. New Jersey: John Wiley \& Sons, Inc.; 2004.

[9] Luckachan GE, Pillai CKS. Random multiblock poly(ester amide)s containing poly(L-lactide) and cycloaliphatic amide segments: synthesis and biodegradation studies. J. Polym. Sci., Part A: Polym. Chem. 2006;44:3250-3260.

[10] Desimone V, Maglio G, Palumbo R, Scardi V. Synthesis, characterization, and degradation of block polyesteramides containing poly(L-lactide) segments. J. Appl. Polym. Sci. 1992;46:1813-1820.

[11] D'Angelo S, Galletti P, Maglio G, Malinconico M, Morelli P, Palumbo R, Vignola MC. Segmented poly(ether-ester-amide)s based on poly(L,L-lactide) macromers. Polymer. 2001;42:3383-3392. 
[12] Katsarava R, Beridze V, Arabuli N, Kharadze D, Chu CC, Won CY. Amino acid-based bioanalogous polymers: synthesis, and study of regular poly(ester amide)s based on bis(alpha-amino acid) alpha, omega-alkylene diesters, and aliphatic dicarboxylic acids. J. Polym. Sci., Part A: Polym. Chem. 1999;37:391-407.

[13] Katsarava R, Ochkhikdze N, Tugushi D, Gomurashvili ZD. AABB-poly(depsipeptide) biodegradable polymers and methods of use US2010/0040664 A1, USA, 2010.

[14] Armarego WLF, Perrin DD. Purification of laboratory chemicals . 4th ed. Oxford: ButterworthHeinemann; 2000.

[15] Paredes N, Rodriguez-Galan A, Puiggali J. Synthesis and characterization of a family of biodegradable poly(ester amide)s derived from glycine. J. Polym. Sci., Part A: Polym. Chem. 1998;36:1271-1282.

[16] Guo K, Chu CC. Synthesis, characterization, and biodegradation of novel poly(ether ester amide)s based on L-phenylalanine and oligoethylene glycol. Biomacromolecules. 2007;8:2851-2861.

[17] Hiltunen K, Harkonen M, Seppala JV, Vaananen T. Synthesis and characterization of lactic acid based telechelic prepolymers. Macromolecules. 1996;29:8677-8682.

[18] Hiltunen K, Seppala JV. The use of different diols in the synthesis of low-molecular-weight lacticacid-based telechelic prepolymers. J. Appl. Polym. Sci. 1998;67:1017-1023.

[19] Ribeiro MP, Espiga A, Silva D, Baptista P, Henriques J, Ferreira C, Silva JC, Borges JP, Pires E, Chaves P, Correia IJ. Development of a new chitosan hydrogel for wound dressing. Wound Repair Regen. 2009;17:817-824.

[20] Maia J, Ribeiro MP, Ventura C, Carvalho RA, Correia IJ, Gil MH. Ocular injectable formulation assessment for oxidized dextran-based hydrogels. Acta Biomater. 2009;5:1948-1955.

[21] Coimbra P, Alves P, Valente TAM, Santos R, Correia IJ, Ferreira P. Sodium hyaluronate/chitosan polyelectrolyte complex scaffolds for dental pulp regeneration: synthesis and characterization. Int. J. Biol. Macromol. 2011;49:573-579.

[22] Gaspar VM, Sousa F, Queiroz JA, Correia IJ. Formulation of chitosan-TPP-pDNA nanocapsules for gene therapy applications. Nanotechnology. 2011;22:015101 (1-2).

[23] Coimbra P, Ferreira P, de Sousa HC, Batista P, Rodrigues MA, Corriea IJ, Gil MH. Preparation and chemical and biological characterization of a pectin/chitosan polyelectrolyte complex scaffold for possible bone tissue engineering applications. Int. J. Biol. Macromol. 2011;48:112-118.

[24] Da Silva MS, Viveiros R, Morgado PI, Aguiar-Ricardo A, Correia IJ, Casimiro T. Development of 2-(dimethylamino)ethyl methacrylate-based molecular recognition devices for controlled drug delivery using supercritical fluid technology. Int. J. Pharm. 2011;416:61-68.

[25] Rashkov I, Manolova N, Li SM, Espartero JL, Vert M. Synthesis, characterization, and hydrolytic degradation of PLA/PEO/PLA triblock copolymers with short poly(L-lactic acid) chains. Macromolecules. 1996;29:50-56.

[26] Skrovanek DJ, Howe SE, Painter PC, Coleman MM. Hydrogen-bonding in polymers - infrared temperature studies of an amorphous polyamide. Macromolecules. 1985;18:1676-1683.

[27] Kaczmarczyk B, Sek D. Hydrogen bonds in poly(ester amide)s and their model compounds. Polymer. 1995;36:5019-5025.

[28] Kaczmarczyk B. FTIR study of hydrogen bonds in aliphatic polyesteramides. Polymer. 1998;39:5853-5860.

[29] Sudha JD. Synthesis and characterization of hydrogen-bonded thermotropic liquid crystalline aromatic-aliphatic poly(ester-amide)s from amido diol. J. Polym. Sci., Part A: Polym. Chem. 2000;38:2469-2486.

[30] Van Bennekom ACM, Willemsen PAAT, Gaymans RJ. Amide-modified poly(butylene terepthalate): thermal stability. Polymer. 1996;37:5447-5459.

[31] De Wit MA, Wang Z, Atkins KM, Mequanint K, Gillies ER. Syntheses, characterization, and functionalization of poly(ester amide)s with pendant amine functional groups. J. Polym. Sci., Part A: Polym. Chem. 2008;46:6376-6392.

[32] Maglio G, Maglio P, Oliva A, Palumbo R. Polyamides containing alpha-aminoacids and hydrophilic oxyethylene groups along the chain. Polym. Bull. 1999;43:191-198.

[33] Wang L, Wang Y, Cao D. Synthesis and characterization of novel biodegradable polyamides containing $\alpha$-Amino Acids. J. Macromol. Sci., Part A: Pure Appl. Chem. 2009;46:312-320.

[34] Wunderlich B. Thermal analysis of polymeric materials. Heidelberg: Springer; 2005.

[35] Yoo ES, Im SS. Effect of crystalline and amorphous structures on biodegradability of poly(tetramethylene succinate). J. Environ. Polym. Degr. 1999;7:19-26.

[36] Helder J, Dijkstra PJ, Feijen J. In vitro degradation of glycine DL-lactic acid copolymers. J. Biomed. Mater. Res. 1990;24:1005-1020. 
[37] Pepic D, Zagar E, Zigon M, Krzan A, Kunaver M, Djonla J. Synthesis and characterization of biodegradable aliphatic copolyesters with poly(ethylene oxide) soft segments. Eur. Polym. J. 2008;44:904-917.

[38] Bezemer JM, Weme PO, Grijpma DW, Dijkstra PJ, Van Blitterswijk CA, Feijen J. Amphiphilic poly(ether ester amide) multiblock copolymers as biodegradable matrices for the controlled release of proteins. J. Biomed. Mater. Res. 2000;52:8-17.

[39] Pinilla IM, Martinez MB, Galbis JA. Synthesis and hydrolytic degradation of stereoregular aromatic poly(ester amide)s derived from D-xylose. J. Polym. Sci., Part A: Polym. Chem. 2010;48:4711-4720.

[40] Armelin E, Franco L, Rodriguez-Galan A, Puiggali J. Study on the degradability of poly(ester amide)s related to nylons and polyesters 6, 10 or 12, 10. Macromol. Chem. Phys. 2002;203:48-58.

[41] Zhang HL, He Y, Li S, Liu XB. Synthesis and hydrolytic degradation of aliphatic polyesteramides branched by glycerol. Polym. Degrad. Stab. 2005;88:309-316.

[42] Marques AP, Reis RL, Hunt JA. The biocompatibility of novel starch-based polymers and composites: in vitro studies. Biomaterials. 2002;23:1471-1478.

[43] Han SI, Kim BS, Kang SW, Shirai H, Im SS. Cellular interactions and degradation of aliphatic poly(ester amide)s derived from glycine and/or 4-amino butyric acid. Biomaterials. 2003;24:3453-3462.

[44] Lampin M, Warocquier-Clérout R, Legris C, Degrange M, Sigot-Luizard MF. Correlation between substratum roughness and wettability, cell adhesion, and cell migration. J. Biomater. Mater. Res. 1997;36:99-108. 